\title{
¿EL “SILICON VALLEY LATINOAMERICANO”?: LA PRODUCCIÓN DE TECNOLOGÍA DE COMUNICACIÓN EN COSTA RICA (1950-2016)
}

\author{
Ignacio Siles González \\ Johan Espinoza Rojas \\ Andrés Méndez Marenco
}

Recibido: 28/11/2015 Aceptado: 29/04/2016

\begin{abstract}
Resumen
Este artículo analiza el crecimiento de un campo institucional de desarrollo de tecnología de comunicación en Costa Rica desde 1950 hasta la actualidad. El estudio hace dos contribuciones: empíricamente, sitúa la producción contemporánea de tecnología de comunicación en Costa Rica en perspectiva histórica; y, a nivel metodológico, suplementa fuentes primarias de datos con entrevistas en profundidad. Se discuten tres procesos: (1) el surgimiento de un campo de producción de tecnología en el país (en la segunda mitad del siglo XX), (2) la estabilización de una industria local (en la década del 2000) y (3) el auge de modelos de producción tecnológica asociados a la noción de emprendedurismo (aproximadamente desde el año 2010). El análisis revela que la convergencia de múltiples lógicas institucionales ha resultado en tensiones que podrían socavar el potencial del campo para el país.
\end{abstract}

Palabras clave: Costa Rica; emprendedurismo; producción; Silicon Valley; startup; tecnologías de información y comunicación (TIC).

\begin{abstract}
This article analyzes the formation of an institutional field around the production of information and communication technologies (ICTs) in Costa Rica since the 1950s to the present day. The paper makes two key contributions: empirically, it situates the contemporary production of ICTs in the country within historical perspective; and, methodologically, it supplements primary data sources with in-depth interviews. Three processes are discussed: (1) The emergence of a technological production field in Costa Rica (in the second half of the 20th century), (2) The stabilization of a local industry (in the 2000s decade), and (3) The rise of models of technological production associated with the notion of entrepreneurship (approximately since 2010). The analysis reveals that the convergence of multiple institutional logics has resulted in tensions that could undermine the potential of the field for the country.
\end{abstract}

Keywords: Costa Rica; entrepreneurship; information and communication technologies (ICT); production; Silicon Valley; startup. 


\section{De "San Jose South" al "Silicon Valley latinoamericano"}

Durante las últimas dos décadas, Costa Rica se ha consolidado como uno de los principales países productores de tecnología en América Latina. En la actualidad, el país constituye el primer exportador per cápita de alta tecnología en la región y el cuarto en el mundo (González Sandoval, 2014; Porter y Ketelhohn, 2002; Rodríguez Clare, 2002; Saliba, 2014). ${ }^{1}$ En el 2015, un grupo de firmas de análisis de inversión catalogó a San José como la "ciudad más competitiva del mundo" en el área de creación de tecnologías de comunicación (Conway, Moody's Analytics, Tractus y Oxford Economics, 2015). Tras la llegada de Intel en 1998, la capital del país obtuvo el fugaz sobrenombre de San Jose South, un "guiño ambicioso a San Jose, California, el corazón de Silicon Valley", en palabras de un reportero del Wall Street Journal (Vogel, 1998).

Recientemente, algunos comentaristas han expresado su deseo de convertir ese guiño en un mensaje más explícito: transformar a Costa Rica en el "Silicon Valley latinoamericano" (BBC, 2012; Chacón Jiménez, 2015; Ciravegna, 2012; Pérez Damasco, 2015). Ante esto, se han implementado diversas iniciativas y esfuerzos en el país con ese propósito. En su conjunto, como lo afirmó el fundador de una red de inversión en startups o emprendimientos dinámicos en el país, este objetivo descansa sobre la premisa de que Silicon Valley provee "metodologías [...] probada[s] y empleada[s] exitosamente alrededor del mundo" (Vargas, 2014: 11).

¿Cuáles factores han influido en la formación y el desarrollo de un campo de producción de tecnología en Costa Rica? ¿Cuáles características ha adquirido la producción de tecnología en el país en las últimas décadas? ¿Cómo se convirtió Silicon Valley en el modelo de desarrollo tecnológico del país? Este artículo provee dos respuestas iniciales a estas interrogantes, al analizar cómo ha evolucionado este sector desde 1950.

En primer lugar, desde el punto de vista empírico, el artículo sitúa históricamente la producción contemporánea de tecnología de comunicación en Costa Rica. La mayoría de las investigaciones explica la creación de este campo de actividad al recurrir a casos concretos, particularmente al surgimiento de empresas productoras de software en los años ochenta o los esfuerzos de atracción de inversión extranjera directa (IED) que culminaron con la llegada de Intel al país en 1998 (Ciravegna, 2012; Nelson, 2009; Paus, 2005; Porter y Ketelhohn, 2002). En cambio, en este artículo se prefirió una visión de proceso cuyo propósito fue vincular las dinámicas actuales de creación de tecnología con las condiciones que las hicieron posibles. ${ }^{2}$

En segundo lugar, desde una perspectiva metodológica, el artículo combina una diversidad de fuentes primarias de datos que han permanecido relativamente dispersas, lo cual ha limitado su potencial heurístico. Además, se complementó el estudio de estas fuentes (e. g. publicaciones y estudios académicos, periódicos, memos e informes institucionales de diferentes épocas) con 26 entrevistas en profundidad a 
una serie de actores claves del campo, incluyendo desarrolladores, emprendedores, directores de empresas e inversionistas, entre otros (la lista completa de personas entrevistadas puede ser consultada al final de este artículo). ${ }^{3}$

La discusión está organizada alrededor de tres procesos principales:

1) Las condiciones históricas que hicieron posible el surgimiento de un campo institucional alrededor de la producción de tecnología en Costa Rica (en la segunda mitad del siglo $\mathrm{XX}$ ).

2) La estabilización de una industria local dedicada a producir tecnología para clientes nacionales e internacionales (en la década del 2000).

3) El auge de modelos de producción tecnológica asociados a la noción de emprendedurismo (aproximadamente desde inicios de la década del 2010).

La conclusión del artículo provee un balance de las tensiones evidenciadas al conducir un estudio que combina la investigación del pasado y del presente. Se argumenta que las identidades de Costa Rica, como país productor de tecnología, son el resultado de la negociación histórica de diferentes lógicas institucionales, es decir, órdenes subyacentes que estructuran un conjunto de ideas en formas de pensamiento coherentes (van der Laan y Kuipers, 2016). Desde ese punto de vista, la construcción del "Silicon Valley latinoamericano" (como la más reciente expresión de esa identidad negociada) ha reposado sobre la formación de un campo institucional con diversas lógicas, actores y relaciones. La convergencia de estas distintas fuerzas también ha resultado en tensiones importantes que podrían socavar el potencial del sector para el país.

Antes de analizar estos procesos, se ofrecen dos aclaraciones conceptuales. La primera se centra en la aproximación teórica adoptada, pues la mayoría de las investigaciones dedicadas a este tema han privilegiado el análisis estructural de su dimensión e importancia económica. Por lo tanto, términos como "industria", "sector", "hub" o "parque" son comunes en la literatura académica. De manera similar, otro concepto empleado frecuentemente es "cluster". Ciravegna (2012) lo utiliza para destacar las "explicaciones socioeconómicas de la formación de redes" alrededor de la producción de tecnología (6). ${ }^{4}$

Como suplemento, en este artículo se prefiere la noción de "campo", formulada por el "nuevo institucionalismo en sociología". Esta idea enfatiza la creación de un conjunto de relaciones y dinámicas entre diversos actores que "constituyen un área reconocida de vida institucional: proveedores clave, consumidores de recursos y productos, agencias reguladoras y otras organizaciones que producen servicios y productos similares" (DiMaggio y Powell, 1983: 148).

Esta perspectiva privilegia las redes de relaciones entre actores, las lógicas que las justifican y las estrategias de trabajo empleadas para definir los límites temporales y espaciales del campo (Scott, 2014). En este sentido, la noción de "campo" permite 
comprender mejor las dinámicas no solo económicas sino también sociales, políticas y culturales que han animado y dado sustento a un sector de actividad o industria. Finalmente, esta aproximación permite también considerar tanto variables estructurales como el rol de los individuos en los procesos de institucionalización (Nicholson y Sahay, 2009b; Silva y Figueroa, 2002).

La segunda aclaración es de carácter conceptual, ya que el término "tecnología" puede ser comprendido de múltiples formas. Este artículo se enfoca, de manera particular, en la creación de productos, conocimientos y servicios desarrollados a partir de la combinación de artefactos, contenidos simbólicos y software (Boczkowski y Siles, 2014). Sin embargo, cuando es posible, también se hace referencia al desarrollo del sector de "alta tecnología" (el cual involucra la producción de dispositivos científicos, médicos, electrónicos y eléctricos, así como a la industria farmacéutica), con el objetivo de ubicar este campo en un contexto más amplio.

\section{Surgimiento e institucionalización del campo (1950-2000)}

Los orígenes del campo de producción de tecnología en Costa Rica tienden a buscarse a partir de las décadas del setenta y ochenta (Jara y Alvarez, 2008; Mata, Matarrita, y Pinto, 2012; PROSIC, 2006; Rodríguez-Clare, 2005). Sin embargo, también se torna posible vincularlos a los inicios de la computación en el país. En la década de 1940, el uso de equipo electromecánico (también llamado "máquinas menores") -el antecesor de las computadoras modernas- era relativamente común en algunas instituciones públicas como los bancos estatales, la Caja Costarricense del Seguro Social y el Instituto Nacional de Seguros, así como empresas privadas con necesidad de procesar grandes volúmenes de datos.

A mediados de los años cuarenta, organizaciones como la Tesorería Nacional y el Banco Nacional de Costa Rica inauguraron las Oficinas Técnicas Mecanizadas (OTM), a las cuales les fue encargado el manejo de dichos equipos (Calderón, 2012b). Estos fueron reemplazados poco tiempo después por computadoras de "segunda generación": se trataba principalmente de computadoras centrales (mainframes) basadas en sistemas de procesamiento por lotes (batch processing) (Ceruzzi, 1998). Dos décadas después, IBM se posicionó como el líder de la industria de la computación en el mundo, incluso en países de América Latina (Medina, 2008). En este contexto, instituciones públicas y empresas privadas arrendaban equipo de computación a IBM y, en menor medida, a otras compañías como Burroughs.

Mediante el aprendizaje autónomo y cursos de formación provistos por algunas empresas (notablemente IBM) y a menudo financiados por agencias estadounidenses (como la Agencia Estadounidense para el Desarrollo Internacional, USAID), en lugares como Estados Unidos y México, varios jóvenes costarricenses se encargaron de la programación de estas computadoras y del desarrollo de rutinas que les permitieran 
procesar datos y agilizar tareas administrativas de las organizaciones. De hecho Marco Antonio Calvo Coronado, quien trabajó como ingeniero de sistemas para varias organizaciones desde 1960 (incluyendo el Banco Central, la United Fruit Company, IBM y MAI de Costa Rica, entre otras), describe el entusiasmo que produjo la llegada de estas computadoras y el trabajo que requirió su implementación:

Yo estaba sentado en el Banco Central estudiando Administración de Negocios. Corté el plan [de seguir estudiando] para recibir una beca [de formación en computación]. Cuando entré al análisis de sistemas, por programación, me di cuenta de que esa era mi carrera. ¡Me enamoré! El análisis de sistemas estaba apenas naciendo. El "programador" [hacía] de todo: sabía de máquinas menores, hacía estudios de factibilidad, los estudios de problemas y [sabía] de programas (entrevista personal, 30 de julio de 2015).

Un ejemplo significativo de producción tecnológica surgida en este contexto fue la construcción de la minicomputadora Basic Four, en la que el costarricense Jorge González Martén ocupó un rol central. Tras su paso como director de la Oficina Técnica Mecanizada del Banco Nacional, González Martén recibió formación en máquinas electromecánicas en Estados Unidos a inicios de la década de 1950 (Calderón, 2012b). Una vez instalado en Nueva York, fundó junto con Walter Oreamuno la compañía Management Assistance Inc. (MAI) en 1955 y estableció en el país la primera oficina de la empresa fuera de Estados Unidos: MAI de Costa Rica. Con el auge de las minicomputadoras (computadoras de menor tamaño que las mainframe, las cuales funcionaban con programas almacenados) en los años sesenta, González Martén propuso y coordinó la creación de la primera minicomputadora comercial de acceso directo (es decir, no requería de tarjetas perforadas): la Basic Four.

Calderón (2012b) resume el papel de González Martén en la creación de la Basic Four, lanzada al mercado en 1971:

1) apoyó la consecución del dinero necesario, impulsando la venta de los equipos electromecánicos, 2) tuvo la visión de cómo quería que fuera la minicomputadora, incluido el hecho de que fuera de acceso directo, y 3) lideró el grupo de aproximadamente diez personas -empleados de MAI y científicos y técnicos de Silicon Valley - responsable del diseño y la producción y se encargó de verificar que el producto desarrollado se ajustara a su visión (3).

Varias organizaciones en Costa Rica, tanto públicas como privadas, adoptaron la Basic Four desde 1975.

Por otra parte la formación académica en universidades públicas dio un impulso vital al desarrollo de tecnología en comunicación en Costa Rica. ${ }^{5}$ Los programas de bachillerato, licenciatura y maestría en Ciencias de la Computación o Informática ofrecidos en universidades públicas del país constituyen los primeros de su tipo en la 
región centroamericana (PROSIC, 2006). En 1973, la Universidad de Costa Rica (UCR) inauguró el bachillerato y licenciatura en Ciencias de la Computación (parte de la Escuela de Matemática) y el bachillerato en Informática (impartido en el Centro de Informática). Estos programas se fusionaron en 1981 al inaugurarse la Escuela de Ciencias de la Computación e Informática (Calderón, 2012a).

Asimismo, el Instituto Tecnológico de Costa Rica (ITCR) estableció la carrera en Ingeniería en Computación Administrativa en 1976. Los graduados de estas carreras se convirtieron en una pieza clave para la creación de las primeras empresas locales destinadas a producir software, en el fortalecimiento de servicios ofrecidos por instituciones públicas y en la operación de distintas empresas en Costa Rica. Para 1982, ambas universidades públicas y la Universidad Autónoma de Centro América ofrecían formación en este campo. Entre 1981 y 1989, un total de 653 estudiantes se graduaron de alguna carrera en esta área (Chaves, 1990).

Entre 1975 y 1985, la microcomputadora se convirtió en un fenómeno comercial. La creación del microprocesador, los programas de software particulares (como BASIC) y las unidades de almacenamiento (como el disquete o floppy disk) transformaron la computadora en una máquina "personal" (Ceruzzi, 1998). En Costa Rica, las computadoras y sus distintos componentes (como accesorios y repuestos) fueron exonerados del pago de impuestos (excepto del impuesto de ventas) en 1985. ${ }^{6}$

Así, la computadora, que había sido casi exclusiva de instituciones públicas y empresas grandes, encontró nuevos usuarios. Para 1988, Chaves (1990) estimó que en el país operaban 30000 microcomputadoras, 500 minicomputadoras y 30 computadoras mainframes. En este contexto surgieron algunas de las primeras empresas dedicadas a la producción y venta de software en el país (Brenes y Govaere, 2008). Dentro de este grupo se pueden mencionar, por ejemplo: Análisis MBC (1988), ArtinSoft (1993), Codisa (1991), Exactus (1987), Latinoamérica Information Technologies (LIT) (1985), Productos Informáticos para el Desarrollo (PRIDES) (1983), Soluciones Integrales (1984) y TecApro (1985). Según Rodríguez-Clare (2005), “Tecapro y ArtinSoft fueron fundadas por profesores universitarios, quienes renunciaron a sus trabajos $y$, junto a sus estudiantes más talentosos, comenzaron a desarrollar software. Por su parte [Codisa] fue fundada por un grupo de estudiantes recién graduados de la universidad" (41). Uno de los principales retos enfrentados por estos empresarios fue obtener financiamiento para desarrollar productos de software de los cuales se conocía poco en el país. El Fondo de Desarrollo Tecnológico (FODETEC), creado con el Préstamo BID/CONICITCONARE a finales de los años ochenta, proveyó a varias de estas empresas algunos fondos mediante préstamos para crear nuevos programas o rediseñar procesos de trabajo (Monge, 2002).

En esta incipiente industria local, los recién graduados universitarios trabajaron en resolver "problemas de facturación, pólizas de seguro, sistemas de crédito, planificación de la producción etc. Era un mercado mucho más orientado a las soluciones específicas 
dentro de una empresa" (PROSIC, 2006: 223). Estos graduados también fueron clave en actividades de programación y mantenimiento de equipos de computación en empresas multinacionales como IBM.

Así, la creación de organizaciones de este tipo en Costa Rica también dio impulso a la exportación de tecnología de comunicación, la cual se convertiría en una dinámica central del campo (Chaves, 1990); pues representó una fuente de financiamiento importante para empresas locales desde su surgimiento. En palabras de Claudio Pinto, cofundador de Exactus: "Empezamos enfocados solo en el mercado local. Rápidamente nos dimos cuenta de que [el mercado] era muy poco profundo [y] nos vimos forzados a empezar a exportar a Centroamérica" (entrevista personal, 28 de octubre de 2015).

Los esfuerzos por estimular la exportación de productos tecnológicos y la llegada de multinacionales al país deben entenderse como parte de un proceso de liberalización económica de mayor envergadura en el contexto de la crisis económica de los años ochenta (Williamson, 1990). En palabras de Rodríguez Clare (2002), esta "estrategia tecnológica", más orgánica que concertada, involucró también varios incentivos fiscales (como la creación de las llamadas Zonas Francas y los Contratos de Exportación) para facilitar las exportaciones tecnológicas y atraer inversión extranjera directa (MIDEPLAN, 2008). A partir de los ejemplos de países como India, Irlanda e Israel, la creación de un campo de producción de tecnología, que combinara empresas locales dedicadas a la exportación y la llegada de multinacionales se concibieron y promocionaron como vías directas al desarrollo (Arora y Gambardella, 2005; Heeks y Nicholson, 2004; Paus, 2005).

En términos generales, los esfuerzos por atraer IED son considerados por la mayoría de investigaciones como el factor individual más significativo en la formación del campo de producción de tecnologías de comunicación en Costa Rica. Un actor clave en las iniciativas por consolidar IED en Costa Rica fue la Coalición Costarricense de Iniciativas de Desarrollo (CINDE), la cual fue creada a inicios de los años ochenta con fondos de USAID como un think tank privado para apoyar al Gobierno en su proceso de sustitución de importaciones. A lo largo de la década de 1990, CINDE concentró sus esfuerzos en atraer la inversión de algunos sectores (electrónico, servicios médicos y turismo). Para Nelson (2009), el éxito de CINDE se debe a IED, a su "independencia tecnocrática" y a una "capacidad transnacional de aprendizaje" (44-46).7

Como resultado de estos esfuerzos, algunas empresas como DSC Communications, Sawtek Inc., Merrimac Industries y Remec se instalaron en el país a mediados de los años noventa. Sin embargo, la corona (e ícono) de la consolidación de Costa Rica como destino de IED en el sector de tecnología fue la llegada de Intel en 1998. Diversas investigaciones han analizado los factores que llevaron a Intel a escoger Costa Rica para instalar una planta de ensamblaje y ensayo e invertir inicialmente $\$ 300$ millones (Larraín, López-Calva y Rodríguez-Clare, 2001; PROSIC, 2006; Rodríguez-Clare, 2002). 
A partir del trabajo de Spar (1998), estos factores pueden resumirse en tres grupos: (a) las características del país (estabilidad política y social, procesos de liberalización económica en curso, experiencia previa con el desarrollo del sector de electrónica, ambiente receptivo a la inversión extranjera, calidad de la educación, ubicación geográfica, clima, entre otros), (b) las tácticas de negociación empleadas por CINDE (apoyadas por el involucramiento directo del entonces presidente, José María Figueres Olsen, y respaldadas unánimemente por los medios de comunicación), y (c) las concesiones específicas dadas a Intel (inventivos fiscales, apoyo en infraestructura de transporte y acuerdos con universidades para fortalecer proyectos de formación profesional).

Sin embargo, la discusión sobre las implicaciones de la llegada de Intel al país se ha dividido entre quienes sostienen que las concesiones excedieron los beneficios obtenidos a corto y mediano plazo (Cordero y Paus, 2009; Hanson, 2001; Paus, 2005; Paus y Gallagher, 2008) y para quienes las ganancias económicas y sociales fueron netamente superiores (Larraín et al., 2001; Monge-González et al., 2015; Nelson, 2009; RodríguezClare, 2002). Mayor consenso existe en la importancia que tuvo la inversión de Intel para ubicar a Costa Rica en el "radar" (Paus, 2005) o el "mapa" (Alonso, 2012) de la IED en tecnología. En su análisis de la relación entre IED y desarrollo, Paus (2005) concluye:

En perspectiva comparativa, el flujo de IED a Costa Rica durante los años 90 fue relativamente menos importante que en el resto del mundo. [...] Pero, dada su condición de país de ingresos medios, Costa Rica sobresale por su capacidad de atraer IED en alta tecnología. Al final del siglo veinte, era el primer país exportador latinoamericano de productos de alta tecnología en exportaciones totales (144-145).

Otro antecedente importante para conformar el campo de producción de tecnología de comunicación en Costa Rica podría ubicarse en la transformación de la computadora de una máquina de cálculo a un medio de comunicación, acentuada por el desarrollo de Internet en el país (Siles, 2008, 2012). El interés incipiente en Internet como nuevo medio para el desarrollo de aplicaciones y tecnologías se tradujo en la creación de nuevas empresas y ocupaciones profesionales. Un resultado de este proceso fue una mayor atención a la creación de contenido para la tecnología (además de software, servicios y equipos tecnológicos). ${ }^{8}$ Algunas de estas empresas iniciaron brindando asesoría a organizaciones de varios tipos sobre aspectos relacionados con conectividad y uso de Internet. Así, hacia finales de la década, estas compañías y agencias adquirieron mayor especialización en la oferta de servicios (particularmente en áreas como diseño o desarrollo Web).

Como resultado del grupo de factores discutidos hasta aquí, en Costa Rica, un sector de la producción de tecnología surgió desde mediados del siglo XX y adquirió, en la década de 1990, características de un campo institucional. Al respecto, Porter y 
Ketelhohn (2002) afirman que, para 1996, un total de 150 empresas se dedicaban a producir software en Costa Rica, todas con menos de 150 empleados. Estas producían un total combinado de $\$ 55$ millones en ventas. Las exportaciones, principalmente a otros países de América Central, ascendían a \$20 millones anuales (Porter y Ketelhohn, 2002). Así, esfuerzos por crear cámaras o grupos empresariales con el propósito de agrupar a un conjunto de organizaciones locales y potenciar sus nexos, reflejan el grado de relativa institucionalización alcanzado por el campo a finales del siglo pasado (Nicholson y Sahay, 2009b).

La primera de estas agrupaciones empresariales fue la Asociación para la Protección de la Propiedad Informática (APPI). Sobre la base de la APPI, en 1998 se fundó la Cámara de Productores de Software de Costa Rica (CAPROSOFT), la cual agrupaba a 16 empresas costarricenses con la "intención de integrar [a] las empresas nacionales de producción de software en un bloque estratégico que [permitiera] fortalecer el sector y desarrollar productos tecnológicos innovadores de alta calidad que se proyecten mundialmente" (CAPROSOFT, 2004). Como lo revela esta descripción, CAPROSOFT agrupaba a organizaciones de diferentes tamaños con objetivos relativamente distintos: mientras las organizaciones más grandes abogaban por fortalecer el mercado local, las compañías más pequeñas buscaban enfocar esfuerzos en proyectos de exportación (Nicholson y Sahay, 2009a). Esta diferencia se mantendría como una tensión importante en los años siguientes.

A finales de la década de 1990, CAPROSOFT tuvo la iniciativa de crear el programa de "Apoyo a la Competitividad del Sector Software de Costa Rica" (PROSOFTWARE). En 1999, el Banco Interamericano de Desarrollo (BID), mediante el Fondo Multilateral de Inversiones (FOMIN), aprobó un préstamo no reembolsable de \$2,5 millones para fortalecer el creciente sector del desarrollo de software en Costa Rica. El programa, ejecutado en los primeros cuatro años del nuevo milenio por la Promotora del Comercio Exterior (PROCOMER), con la colaboración de CAPROSOFT y del Centro Nacional de Alta Tecnología (CENAT), estaba enfocado en tres áreas específicas: la formación de recurso humano, la gestión empresarial de organizaciones en el sector (mediante la introducción de sistemas de calidad) y el rol institucional de CAPROSOFT en la consolidación del campo. El programa involucró una serie de estudios y consultorías para desarrollar software en el país (Nicholson y Sahay, 2008, 2009b; Pinto et al., 2009). El trabajo de la Cámara y de algunos actores del sector en los años siguientes estuvo orientado por los resultados de estos estudios.

\section{La estabilización del campo de producción de tecnología de comunicación (2000-2010)}

Al inicio del nuevo siglo, el campo de producción de tecnologías de comunicación en Costa Rica involucraba una serie de actores interrelacionados (por ejemplo, 
desarrolladores de tecnología, emprendedores, universidades públicas y privadas, agencias e instituciones gubernamentales, pequeñas y medianas empresas nacionales, multinacionales, asociaciones privadas, entidades financieras y clientes en varios países, entre otros). A lo largo de la década del 2000, este sector se desarrolló en función de una doble articulación. Por un lado, la industria local se estabilizó y estuvo notablemente orientada hacia la exportación a mercados internacionales. Además de las empresas pioneras de los años ochenta, en esta década surgieron otras organizaciones dedicadas a la creación de una diversidad creciente de servicios y tecnologías (por ej. videojuegos y animación digital). Los cálculos sobre la cantidad de organizaciones costarricenses de este tipo varían. PROSIC (2007), con base en datos de PROCOMER, calculó que en el año 2006 había alrededor de 295 empresas en el país, mientras que otra investigación aseguró que el número ascendía a 600 (Pinto et al., 2009).

Por otro lado otro, empresas multinacionales continuaron instalándose en Costa Rica gracias al fortalecimiento de iniciativas de atracción de IED. Con el cambio de década, CINDE reenfocó su estrategia particularmente en los sectores de servicios y soporte en tecnología de comunicación (incluyendo los llamados contact centers), ingeniería y diseño. Multinacionales como Hewlett-Packard y la agencia de comunicación Schematic abrieron oficinas en el país durante esos años. A mediados de la década del 2000, según Pinto y colaboradores (2009), operaban "casi 95 empresas de tamaño grande y mediano, principalmente en industrias vinculadas con los componentes y los servicios habilitados, las cuales generaron unos 2,200 millones de dólares y emplearon a alrededor de 24,000 personas" (16).

La coexistencia de ambos tipos de organizaciones no estuvo desprovista de controversia, pues expresiones como "guerra," "sangrado" y "canibalismo" fueron utilizadas de manera común por personas entrevistadas en el marco de esta investigación para referirse a las dificultades de reclutar y mantener a los trabajadores en sus organizaciones y a la competencia que caracteriza a estos procesos (en la conclusión se consideran las implicaciones de esta controversia con mayor detalle). Según el fundador de una empresa creada a inicios de los años 2000, su compañía llegó a perder en un solo día a cinco trabajadores que aceptaron puestos de trabajo en organizaciones multinacionales. Ante esto, la compañía adoptó informalmente el eslogan: "aumentar salarios o morir" (entrevista personal, 20 de abril de 2016).

La consolidación de una cámara empresarial que fungiera como "vocera" de los actores y como representante de sus intereses fue un factor importante en la estabilización del campo en esta década. En este sentido, el desarrollo de CAPROSOFT en los primeros años del nuevo milenio puede pensarse como una metáfora de la configuración del sector.

Como se apuntó anteriormente, el surgimiento de esta Cámara estuvo marcado por una tensión entre dos tendencias: el énfasis en el mercado local y la búsqueda de nexos internacionales para facilitar las exportaciones. Según Nicholson y Sahay (2009a), 
la segunda se convirtió en la postura dominante al interior de CAPROSOFT en sus primeros años de funcionamiento, gracias a la iniciativa de diversos actores (entre ellos Alexander Mora Delgado, quien presidía la Cámara desde el 2001). Esto se tradujo notablemente en esfuerzos por ampliar el margen de acción de la Cámara y la naturaleza de sus integrantes (incluyendo, por ejemplo, no solo a productores de software sino también a empresas de servicios basados en tecnología, como contact centers).

En el 2004, en el contexto de este proyecto de ampliación de objetivos y participantes, CAPROSOFT se convirtió en la Cámara de Tecnologías de Información y Comunicación (CAMTIC) ${ }^{9}$ y pasó a agrupar a 111 empresas del sector (en especial a aquellas dedicadas a ofrecer servicios y tecnologías para Internet).

Más allá de cualquier iniciativa concreta, puede argumentarse que el éxito de CAMTIC, en la primera década del siglo, radicó en su capacidad para posicionarse como un portavoz del campo o un "punto de pasaje obligatorio" en su institucionalización y desarrollo (Callon, 1986). Dos iniciativas de esta Cámara, lanzadas en el 2004, revelan la forma en que esta imaginaba el progreso del sector y su rol como vocero institucional.

La primera fue una estrategia para desarrollar el campo de producción de tecnología de comunicación llamada "Costa Rica: Verde e Inteligente". Para justificar la importancia del sector, la estrategia revisitó los orígenes mismos de la fundación de Costa Rica como república. En sus primeras páginas, se citaba un discurso al Congreso de José María Castro Madriz en el que se proponía a "la ciencia y la técnica" como los únicos caminos para no condicionar el desarrollo de Costa Rica a los imperativos de sociedades ajenas (CAMTIC, 2004). ${ }^{10}$ De manera más significativa, la estrategia señalaba que el desarrollo de soluciones empresariales de software (el cual había sido central en la formación del campo en los años ochenta) había perdido demanda en mercados internacionales.

En ese contexto, se recomendaba varios mecanismos y procesos para redefinir el futuro del campo: el fortalecimiento de capacidades gerenciales y de administración de proyectos en empresas costarricenses, la búsqueda de apoyos financieros, la creación de mayores vínculos entre los actores del sector y la definición de una política nacional para estimular la producción de tecnología. La estrategia estaba orientada hacia un objetivo claro: convertir a Costa Rica en un "importante proveedor internacional de productos y servicios de tecnologías de información y comunicación innovadoras y de alto valor" (CAMTIC, 2004: 10). En un giro irónico a las palabras de Castro Madriz, la identidad del campo quedaba relativamente condicionada a las necesidades del mercado internacional, según CAMTIC.

La segunda iniciativa, asociada a la estrategia "Costa Rica: Verde e Inteligente", fue un nuevo programa financiado por BID-FOMIN, llamado "Link", el cual buscaba operacionalizar algunas de las recomendaciones formuladas en la estrategia "Costa Rica: Verde e Inteligente". Dotado de \$7,5 millones, el programa incluía la realización 
de subsidios, préstamos, cursos de formación y consultorías. Los proyectos se ejecutaron en función de dos grandes ejes: (a) el estímulo a la creación y el financiamiento de empresas de producción de tecnologías y (b) la promoción de la exportación.

En concreto, el programa constó de cuatro iniciativas a cargo de diferentes unidades ejecutoras. Primero, se desarrollaron varios planes para facilitar la exportación de tecnología (Link Exportación), a cargo de CAMTIC. Según Sanz y Porras (2012), este fue el componente más exitoso de Link. En su mayoría, las actividades se centraron en la realización de ferias, entrenamientos y actividades de formación. El segundo componente fue un centro de incubación para empresas del sector (Link Incubación). La entidad encargada de implementar este centro fue Parque Tec, una incubadora de empresas de software creada en el 2004 por Marcelo Lebendiker, con el propósito de "proveer a emprendedores con oportunidades de aprender de manera experiencial [y] un programa de entrenamiento [coaching] liderado por un grupo de psicólogos sociales" (Lebendiker, 2005: 181).

El tercer componente del programa contemplaba el desarrollo de una red de inversionistas "ángeles" para estimular emprendimientos (Link Inversiones), coordinada por la Fundación Mesoamérica. A lo largo de sus 4 años de funcionamiento, el programa recibió 353 planes de negocios, de los cuales se invirtió en 6 (Sanz y Porras, 2012). Finalmente, el último componente del programa constaba de la creación de soluciones financieras para las pequeñas y medianas empresas de la industria (Link Financiamiento). Este componente no fue implementado por la entidad encargada (Desyfin).

Ahora bien, para respaldar la estrategia y el programa, la Cámara publicó un informe sobre el "Estado Nacional del Software" en el país a mediados de la década (CAMTIC, 2005). Entre muchos otros datos, este documento señalaba que las aplicaciones "para y sobre Internet" y aquellas destinadas a facilitar los procesos de "administración y gestión" se habían convertido en el principal tipo de tecnología de comunicación creada en el país. Se afirmaba también que la producción de software había deparado un total de \$173 millones en ventas en ese año. Finalmente, según el informe, la exportación de productos tecnológicos había ganado mayor importancia en la primera mitad de la década. El destino de las exportaciones también había variado:

América Central [perdió] importancia como destino de exportaciones para el sector de software (de más del 60\% en 2004 cayó al 40\% en el 2005). No obstante, [cobraron] relevancia las exportaciones a Estados Unidos - que apenas alcanzaban el 13.3\% del total en el 2004-y hoy representan más de un quinto de las exportaciones del sector. México hoy representa un 15\% versus el 9.5\% que se destinaba a ese mercado en el 2004 (CAMTIC, 2005: 13).

Mediante estas iniciativas, CAMTIC puso sobre la mesa de discusión nacional una agenda de temas para pensar y construir el desarrollo del campo. A mediados de la década del 2000, la Cámara trabajaba activamente en la promoción de esta agenda 
y en algunas recomendaciones para solventar lo que veía como sus principales retos. Entre esas recomendaciones figuraban: mejorar la infraestructura existente en telecomunicaciones, dotar a organizaciones instaladas en el país de mayor y mejor "recurso humano" y contar con políticas públicas apropiadas para incentivar el desarrollo del campo y la exportación de productos como software, en particular.

Estas recomendaciones encontraron eco en varios trabajos de investigación de la época (Baraya, Brenes, y Budden, 2008; Nicholson y Sahay, 2008). Un estudio conducido por investigadores de varias organizaciones (incluyendo la UCR, CAMTIC y otras) en más de 80 empresas del campo, concluyó: "[Existe una] necesidad de que el Estado retome un papel más proactivo, de facilitador en la planificación y con mucha claridad en el diseño de políticas públicas efectivas para el desarrollo del sector" (Pinto et al., 2009: 44). Medios de comunicación difundieron estas preocupaciones, notablemente la falta de recurso humano capacitado para satisfacer las necesidades de empresas locales y multinacionales y, por lo tanto, para lograr el crecimiento del sector.

Una investigación publicada por la Comisión Asesora en Alta Tecnología (CAATEC), organización privada sin fines de lucro, muestra algunas de las principales características de las empresas productoras de tecnología de comunicación en el país a finales de la década del 2000 (Monge-González y Hewitt, 2008). El estudio adoptó una terminología relativamente estandarizada para clasificar a una muestra de 117 empresas costarricenses y 81 multinacionales en cuatro grupos: "componentes" (hardware), "software", "servicios directos" (relacionados con la creación de tecnología)" y "servicios habilitados" (no vinculados a las tecnologías, pero dependientes de ellas para su funcionamiento).

Según la investigación, las empresas costarricenses estaban predominantemente destinadas a la oferta de servicios directos (casi $60 \%$ ) y creación de software $(21,4 \%)$, mientras que las multinacionales estaban orientadas a la oferta de servicios habilitados (53\%) (notablemente las compañías de outsourcing) y a la producción de hardware (42\%). Otra diferencia importante identificada en el estudio se centraba en el tamaño de estas organizaciones. Según Monge-González y Hewitt:

Casi tres cuartas partes $(74,4 \%)$ de las empresas costarricenses son micro o pequeñas empresas, siendo el resto principalmente empresas medianas (20.5\%). [...] Las empresas [multinacionales] son casi trece veces más grandes, en promedio, que las empresas costarricenses (344,1 y 26,9 empleados por empresa, respectivamente). [...] Las empresas de productos de software son las más pequeñas de todos los tipos de empresas tanto [multinacionales] como costarricenses (2008: 54-56).

El caso de la compañía costarricense Fair Play Labs permite comprender cómo se conjugaron algunas de las dinámicas que marcaron el desarrollo del campo de producción de tecnología en el país durante la década del 2000. Fair Play Labs fue ideada 
en 2003 por Claudio Pinto, cofundador de una de las primeras empresas productoras de software en el país (Exactus). Motivado por una conversación con su hijo de 7 años, un ávido jugador de videojuegos, Pinto se interesó en las dinámicas de desarrollo de esta industria: "En ese momento, pasé de ser un jugador a un ingeniero tratando de entender cómo se construye [un videojuego]. Empecé a leer, empecé a ir a [conferencias]" (entrevista personal, 28 de octubre de 2015).

Después de una primera fase de experimentación y aprendizaje, que se extendió por un periodo de casi dos años, Pinto se convenció de la posibilidad de exportar videojuegos fuera del país. Un correo electrónico enviado por CAMTIC sobre una oportunidad de negocios deparó en el primer cliente de Fair Play Labs. La empresa apostó por el outsourcing de servicios como motor para crear productos propios. En 2008, tras algunos intentos fallidos de publicar sus juegos, Fair Play Labs vislumbró la apertura la App Store de Apple (y su plataforma de desarrollo en el sistema operativo iOS) como la oportunidad ideal para lanzar sus productos. Cuatro meses después de la apertura de la App Store, la empresa publicó su primer juego: WackyLands Green. Desde entonces, Fair Play Labs ha enfocado su trabajo en estas grandes áreas: outsourcing y propiedad intelectual propia. Para esto, la empresa se ha nutrido (casi en partes iguales) de programadores y diseñadores, quienes trabajan en colaboración.

La década del 2000 concluyó en Costa Rica con agitadas discusiones sobre el significado de la aprobación del Tratado de Libre Comercio (TLC) con Estados Unidos, Centroamérica y República Dominicana para el desarrollo del campo (Jara y Alvarez, 2008). La discusión respecto a las tecnologías de comunicación se centró en temas como las implicaciones de la apertura del mercado de telecomunicaciones y los posibles beneficios que traería el Tratado para la exportación de productos y servicios del sector. Tras la aprobación del TLC, por un estrecho margen en el referéndum de finales de 2007, CAMTIC — nuevamente como vocero del campo- celebró la posibilidad de exportar software a Estados Unidos sin pagar impuestos. En palabras de un sitio de información empresarial, este se anunciaba como un camino seguro para convertir finalmente a Costa Rica en un "país de TI [tecnología de información]" (Nixon, 2007).

Hacia el final de la década, CAMTIC (2009) revisitó la estrategia de desarrollo que había formulado en 2004 y lanzó una versión actualizada: “Costa Rica: Verde e Inteligente 2.0". Las áreas de trabajo más importantes identificadas por la estrategia mostraban poca diferencia con respecto de la versión anterior (y de otros estudios realizados en la década). Se señalaba así la necesidad de políticas públicas apropiadas, de desarrollo de "recurso humano", de mejoramiento de condiciones de financiamiento y de fortalecimiento del rol institucional de CAMTIC.

Según el informe, el número de organizaciones productoras de tecnología activas en el país al final de la década había ascendido a 805, principalmente en las áreas de venta de servicios y desarrollo de software. Las ventas anuales del sector en 2010 alcanzaban los "\$3.500 millones, un 10.6\% del PIB; \$2.800 millones en exportaciones 
(28.8\% del total) y un total de 54.700 empleos (3.4\% de la fuerza laboral)" (CAMTIC, 2009: 10). Entre las propuestas más significativas estaba la creación de una clasificación extensa de los actores del sector. De acuerdo con la propuesta, las empresas que operaban en el país podían organizarse en función de nueve categorías: desarrollo de software, multimedia digital, e-commerce, e-learning, tecnologías de información, telecomunicaciones y redes, comercialización de tecnologías, servicios habilitados por tecnologías y manufactura.

Más allá de su valor práctico, esta clasificación evidencia la proliferación de servicios y tecnologías desarrolladas en el país durante la década del 2000. Un ejemplo de esta diversificación es el surgimiento de empresas costarricenses dedicadas a producir animación digital y videojuegos. Para finales de la década, al menos siete empresas costarricenses exportaban productos de animación digital fuera del país (y habían formado un grupo empresarial para potenciar sus exportaciones en conjunto), seis estaban dedicadas a la producción de videojuegos, al menos dos creaban aplicaciones de e-learning y no menos de ocho agencias de publicidad ofrecían servicios de comunicación digital (que incluían tanto un componente de estrategia como de producción de tecnología) (PROSIC, 2011). Además, el surgimiento de carreras universitarias en el sector privado, como Animación Digital o Diseño de la Interacción en la Universidad Véritas (fundada en la década siguiente), también ha ayudado a institucionalizar dinámicas de producción de este tipo de tecnologías de comunicación.

\section{El momento del emprendedurismo (aproximadamente desde 2010)}

En los últimos años, el campo de producción de tecnología en el país ha estado marcado por el desarrollo de las mismas dinámicas consideradas en párrafos anteriores. Monge et al. (2015) encontraron que, en el 2013, el número de compañías del sector ascendía a 873, de las cuales 587 eran costarricenses y 286 multinacionales. Además de la expansión del tipo de productos creados y del trabajo continuo de organizaciones como CINDE ${ }^{11}$ y PROCOMER para estimular la producción y exportación de tecnología desde Costa Rica, la creación de tecnologías en el país ha estado caracterizada en años recientes por un giro hacia los valores y métodos de trabajo asociados a Silicon Valley. ${ }^{12}$ Diversos actores del campo han encontrado recientemente en el modelo del Silicon Valley, particularmente en la lógica y los principios del emprendedurismo, una forma ideal de expresión y articulación.

En ese sentido, puede afirmarse que esta lógica experimenta un auge en el país como forma de entender las dinámicas que dan sustento y prospectiva al sector de producción tecnológica. Al retratar el momento que vive el emprendedurismo en este campo, no se pretende sugerir que otras dinámicas de creación de tecnología de comunicación quedaron invalidadas. Se trata, más bien, de identificar nuevas lógicas institucionales que suplementan el repertorio de aproximaciones discutidas anteriormente. 
El crecimiento de Silicon Valley desde los años 30 estuvo sustentado en una mezcla de factores como la adopción de ciertas prácticas, competencias, conjuntos de conocimientos, estructuras organizativas y dinámicas culturales (Saxenian, 1994). El emprendedurismo ha ocupado un rol privilegiado en este entramado de prácticas e instituciones que definen a Silicon Valley. ${ }^{13}$ Según Lécuyer, “a lo largo de 40 años, innovadores-emprendedores desarrollaron nuevas formas de manufactura de componentes electrónicos avanzados [...] [que] permitieron a empresas locales introducir productos innovadores. Los ingenieros e innovadores de Silicon Valley también aprendieron a manejar procesos y personas" (2006: 5).

Las dinámicas que caracterizan al ecosistema de Silicon Valley han sido exportadas a nuevos lugares, en parte gracias al rol de actores a los que Saxenian (2006) llama los "nuevos argonautas". En su mayoría, se trata de hombres jóvenes que, gracias a sus redes de contacto y tras su paso por sitios como Silicon Valley, regresan a sus países de origen y "pronto identifican nuevas oportunidades de mercado, obtienen capital, construyen equipos de trabajo y establecen asociaciones con productores especializados situados en lugares lejanos" (5). Para Saxenian, este mecanismo ha sido central en la reproducción de Silicon Valley desde la década de los 90 y en el desarrollo de industrias de producción de tecnología en lugares con altas inversiones en materia educativa, pero que no han apostado por la IED como principal estrategia de desarrollo (por ejemplo, China, India y Taiwan).

Desde luego, experiencias de emprendedurismo en la producción de tecnología pueden ubicarse desde los orígenes mismos del campo en Costa Rica. Sanz y Porras (2012) narran las experiencias de Richard Beck y Carlos Mora, inversionistas de Estados Unidos y Venezuela, respectivamente, quienes procuraron "desarrollar un mini Silicon Valley en Costa Rica" desde finales de los años 90 (177). Según los autores, su estrategia fue "crear una masa crítica de compañías de tecnología de información mediante la inversión en un grupo de compañías con negocios interrelacionados" (Sanz y Porras, 2012: 177). Además de las inversiones de Beck en Cenfotech y ArtinSoft, el dúo invirtió en empresas como Interamerica, Lidersoft y Predisoft (Condo, Sanz y Williams, 2005; Sanz y Lessiza, 2013).

Asimismo, muchas de las primeras empresas locales productoras de software también fueron fundadas en los años ochenta "por jóvenes profesionales con un fuerte impulso emprendedor" (Rodríguez-Clare, 2005: 37). Empresas pioneras en la producción de software, como Exactus, consiguieron varias rondas de inversión de capital desde mediados de los años noventa.

Como se discutió en la sección anterior, desde mediados de la década del 2000 se implementaron en el país dinámicas de producción de tecnologías de comunicación que promovían los valores asociados al emprendedurismo y a la toma de riesgos en la innovación, por ejemplo Parque Tec, la incubadora especializada en 
software (Lebendiker, 2005). Fiel a sus raíces empresariales, CAMTIC también incentivó dinámicas de emprendedurismo en el conjunto de iniciativas que desarrolló en la década del 2000 (notablemente con Link Inversiones).

A inicios de la década del 2010, estos esfuerzos adquirieron mayor fuerza institucional. En su estudio sobre la situación del emprendedurismo en Costa Rica, Petry y Lebendiker (2011) concluyeron:

En los últimos años se nota un creciente esfuerzo por incorporar el fomento al espiritu emprendedor y desarrollar programas para estimular la implementación de nuevas ideas entre [...] estudiantes. La tasa de actividad emprendedora en el país se acerca en promedio a la de los países con mejores indices de desarrollo humano con economías basadas en eficiencia (1).

Para cierto grupo de jóvenes, en su mayoría hombres con títulos universitarios en carreras como Ciencias de la Computación, Informática y Administración de Negocios, el emprendedurismo ha brindado un nuevo estímulo al campo de producción de tecnología de comunicación. Al respecto, Néstor Villalobos, un graduado de Publicidad de la UCR quien desarrolló una serie de proyectos (incluidos un videojuego llamado Tweet Land y una agencia de producción de tecnología y contenido digital), lo define como una "cultura". En sus palabras:

Algo que ha pasado en los últimos dos años o tres años es que explotó la cultura emprendedora en Costa Rica, y emprendedora digital o tecnológica, por decirlo así. [...] La cultura emprendedora aqui en Costa Rica por lo menos está en boom teórico. En la teoría, ya todo mundo sabe lo que son los conceptos, saben qué es un pitch, una lean startup... saben todo (entrevista personal, 19 de mayo de 2015).

Desde este punto de vista, además de un nuevo impulso, el emprendedurismo también provee herramientas concretas de trabajo a los actores del campo (es decir, las metodologías y prácticas implementadas en Silicon Valley). Otras formas comunes de referirse a este conjunto de proyectos son las de "ecosistema" y de "comunidad", las cuales enfatizan los sentimientos de similitud, interconexión y cercanía existentes entre personas que han adoptado estas nociones.

La estructura de organización privilegiada en este modelo de producción de tecnología es la startup, la cual consiste en un proyecto u organización emergente dedicado a producir un servicio o tecnología y, en paralelo, a la búsqueda de un modelo de negocios escalable. La definición de startup es relativa y objeto de discusión entre actores, pues, por ejemplo, José Cayasso, creador de algunos proyectos de emprendimiento en tecnología de comunicación (los cuales se analizan en párrafos posteriores), elabora una definición propia al contrastar las startups con pequeñas y medianas empresas (PYMES): 
Startup parece ser la nueva palabra de moda entre los ticos, iy para bien! [...] [P]or definición todos los startups son PYMES. Sin embargo, no todas las PYMES son startups. [...] [Startup es] un proyecto innovador en capacidad de crecer de manera rentable, rápida y sostenible en el tiempo. Un producto o servicio que genera alto valor agregado y puede diferenciarse de otros porque tiene un modelo de negocio innovador que le da una ventaja competitiva-tecnológica o no-para convertirse en una mediana empresa en menos de 5 años (Cayasso, 2015: 1, 3, 5, 6).

Como se discutió en la sección anterior, múltiples actores del campo consideran que la falta de condiciones apropiadas para desarrollar el sector es uno de sus principales retos. ${ }^{14}$ Ante esto, parte del trabajo asociado al desarrollo de startups y proyectos de emprendimiento en tecnología de comunicación ha estado dedicado a crear estas condiciones mediante varios tipos de iniciativas. Actualmente, por ejemplo, además de bancos, instituciones públicas (como el Ministerio de Economía, Industria y Comercio, MEIC) y asociaciones privadas (como la Cámara de Comercio de Costa Rica), existen en el país al menos siete incubadoras o aceleradoras para startups y empresas emergentes o en desarrollo: Auge (de la UCR), Carao Ventures, Cie-Tec (del ITCR), GS Uno Costa Rica, UNA Incuba (de la Universidad Nacional), Parque La Libertad y Parque Tec.

La premisa de estas entidades es que los productos creados mediante iniciativas de emprendimiento requieren de formas particulares de trabajo y financiamiento que distan de dinámicas organizacionales tradicionales. Carao Ventures, fundada por Allan Boruchowicz y Adrián García en 2012, tiene entre sus principales funciones establecer un mecanismo de financiamiento poco común en el campo de la producción de tecnología en Costa Rica: el capital de riesgo. Carao también puede interpretarse como resultado del trabajo de los "nuevos argonautas".

Ademas, la lógica del emprendedurismo también ha encontrado algún sustento gubernamental. El MEIC aprobó la primera Política Nacional de Emprendimiento ("Costa Rica Emprende") en 2010 y lanzó el concurso de capital semilla del Sistema de Banca para el Desarrollo (durante la administración de Laura Chinchilla Miranda). De manera más sistemática, y con mayor ímpetu, varios actores del sector privado (sin mayor participación estatal) han implementado iniciativas para crear condiciones de desarrollo del emprendedurismo. En 2008, una organización sin fines de lucro ("Yo Emprendedor") surgió con ese propósito.

En lo que respecta a la producción de tecnología, la mayoría de estas iniciativas han estado destinadas a establecer vínculos entre diferentes tipos de actores y a generar espacios de intercambio. Por ejemplo, en 2012, un grupo de emprendedores creó una serie de encuentros conocidos como Tico Founder Speed Dating. Mediante el formato de "citas rápidas" (speed dating), estos encuentros buscaban que potenciales inversionistas tuvieran la oportunidad de conversar sobre ideas con desarrolladores 
de tecnología. De manera similar, otro grupo de jóvenes organizó en 2014 la versión local del evento Startup Weekend, en la cual las personas participantes presentaron sus ideas (en menos de 60 segundos) a un público compuesto de pares y jurados.

De hecho, reuniones formales e informales de conversación, conocidas como meetups, se realizan de manera relativamente frecuente en la actualidad. La reunión con quizá más participación es First Tuesday, un evento organizado por Carao Ventures, en el que participan habitualmente personas del sector para escuchar conferencias sobre temas afines a sus intereses.

Dos startups costarricenses ejemplifican las trayectorias que siguen los proyectos de este tipo y las aspiraciones de algunos de sus impulsores. En 2011, un graduado de la carrera de Animación Digital en la Universidad Véritas, llamado José Cayasso, desarrolló un proyecto dedicado a la creación de estrategias de comunicación digital: Saborstudio. Uno de sus primeros proyectos fue un juego para el sistema operativo iOS (de Apple) llamado Pota-Toss, lanzado en 2012. El juego utilizaba la tecnología GPS de teléfonos celulares para generar contenido relacionado con la localización de su usuario.

El proyecto logró obtener aproximadamente \$14,000 mediante una plataforma de recaudación de fondos por Internet (Kickstarter). Aunque no llegó a una siguiente fase de desarrollo debido a falta de patrocinio, Pota-Toss fue la puerta de entrada a lo que Cayasso describe como "el ecosistema de startups en Costa Rica" (entrevista personal, 19 de agosto de 2015). El proyecto obtuvo amplia cobertura en medios de comunicación internacionales, incluido el popular sitio de noticias sobre tecnología TechCrunch, y fue seleccionado por una aceleradora de startups con sede en Nueva York (DreamIt Ventures).

Sobre la base de esta experiencia, en 2013 Cayasso se aventuró a crear una nueva startup: una aplicación en línea que automatiza la creación de presentaciones con diseños gráficos predeterminados (Slidebean). Con este nuevo proyecto, ganó el concurso de capital semilla del Sistema de Banca para el Desarrollo y fue seleccionado por el programa Startup Chile y por otra aceleradora de startups en Estados Unidos (500 startups).

Otro caso es el de Gilbert Corrales, un ingeniero en sistemas graduado del ITCR instalado en Newcastle upon Tyne, Inglaterra, quien trabaja en otra startup costarricense: Leaf, pues Corrales la describe como "el primer servicio de música para la generación pos-millenial”, es una aplicación para tecnologías móviles que permite descubrir y escuchar música. Al igual que Cayasso y García, Corrales ejemplifica el rol del "nuevo argonauta" en la implementación de modelos de producción tecnológica inspirados en Silicon Valley. Dicho sea de paso, el desarrollo de Leaf también ha estado marcado por procesos de incubación y aceleración en redes de trabajo internacionales. Según Corrales: 
Empezamos Leaf en Costa Rica, desde [mi] casa. Mi esposa [y yo] convertimos la mitad de la casa en oficina y empezamos ahí. Como a los cuatro meses, nos contactaron de Estonia y nos invitaron a participar de un programa de aceleración. El programa como tal no nos agregó mayor valor, pero lo que hizo fue darnos confianza de que podiamos llevar Leaf a un [escenario] mundial (entrevista personal, 23 de junio de 2015).

Posteriormente, Leaf fue seleccionada por Ignite, una red aceleradora de startups en el Reino Unido (con sede en Newcastle) para formar parte de su programa de incubación.

El proyecto de convertir a Costa Rica en el "Silicon Valley latinoamericano" es visto con precaución o inclusive escepticismo por actores que han adoptado estas dinámicas de trabajo. En la práctica, este proyecto se traduce principalmente en el ajuste de ciertos métodos de creación de tecnología como un mecanismo para estimular la exportación de productos y servicios a un mercado global. Se trata, por lo tanto, de una meta simbólica más que literal.

En este contexto, la identidad de "startup tica" es manejada de forma estratégica. Por una parte, varios desarrolladores consideran que sus proyectos son "ticos" en el sentido en que fueron pensados y creados desde el país. Esta noción expresa una convicción de que "Costa Rica tiene algo para aportarle al mundo" y "su voz es importante", en palabras de Paul Fervoy, quien trabaja en el campo desde la década de los 90 y actualmente dirige una empresa de analítica Web, además de asesorar a emprendedores. De manera similar, Corrales expresa: "Somos cuatro ticos los que hacemos esto [Leaf]. La forma en que trabajamos es "tica", hay cosas de familia. [...] Seguimos siendo ticos y Leaf es tico" (entrevista personal, 23 de junio de 2015).

Por otra parte, desarrolladores afirman que esto no debe confundirse con el deseo de crear aplicaciones exclusivamente para Costa Rica. Por el contrario, el objetivo común de la mayoría de los proyectos de este tipo es identificar una idea con potencial de adopción internacional. Al respecto, Corrales amplía: "[El] mercado más pequeño es Latinoamérica. Si usted empieza pensando en Costa Rica, es una PYME y no va a ningún lado" (entrevista personal, 23 de junio de 2015). A largo plazo, la meta de varios desarrolladores e inversionistas en este campo consiste en crear una tecnología o un servicio que pueda ser adquirido por una empresa de mayor envergadura a nivel mundial y reiniciar así el ciclo de creación de una startup a partir de una nueva idea.

A pesar del auge de este tipo de iniciativas y proyectos, múltiples actores critican la falta de medios para crear startups y emprendimientos, como leyes y políticas públicas, estímulos a la innovación local y, notablemente, mecanismos para obtener capital que se ajuste al tipo de procesos que caracterizan a estas organizaciones y no a una PYME en su sentido tradicional (Lebendiker Fainstein, Herrera González y Velásquez López, 2015). De manera similar, Sanz y Porras (2012) afirman que “quizá es 
la falta de un ecosistema completo lo que limita el desarrollo de soluciones financieras más exhaustivas" (186) para fomentar el desarrollo del campo.

\section{Costa Rica, "nación startup"}

Este artículo analizó la formación de un campo institucional alrededor de la producción de tecnologías de comunicación en Costa Rica. Así, se explica cómo surgieron y se desarrollaron diversas lógicas institucionales y cómo ciertos actores las han adoptado para sostener diferentes tipos de relaciones. En este campo convergen actualmente programadores, diseñadores, desarrolladores de tecnología, inversionistas, emprendedores, universidades públicas y privadas, agencias e instituciones gubernamentales, empresas locales, multinacionales, asociaciones privadas, entidades financieras, clientes nacionales e internacionales, unidades de investigación, entre otras. Producto de esto, las identidades de Costa Rica como país productor de tecnología (incluyendo el proyecto más reciente de convertirse en el "Silicon Valley latinoamericano") pueden entenderse como el resultado de la negociación histórica de estas diferentes lógicas institucionales y de las relaciones entre los actores que integran el campo.

El análisis reveló dos tensiones importantes que son consecuencia de la conformación de este campo de creación tecnológica como espacio de convergencia de actores y lógicas. En primer lugar, la construcción del campo de producción de tecnología en Costa Rica ha reposado sobre una disyuntiva importante entre la creación de condiciones apropiadas para facilitar el surgimiento y desarrollo de organizaciones locales versus el estímulo dado a la inversión extranjera. Esta dinámica ha resultado en una tensión al interior del campo entre actores que consideran que las iniciativas locales reciben pocos incentivos (comparado a empresas multinacionales) y otros para quienes los aportes de las multinacionales al país son vitales (principalmente desde el punto de vista económico y en la circulación de conocimiento). ${ }^{15}$

Esta tensión puede apreciarse, por ejemplo, en las percepciones que tienen los productores de tecnología sobre las empresas multinacionales instaladas en Costa Rica. Algunos, quienes laboraron en algunas de estas empresas, definen su paso por ellas como una experiencia central de aprendizaje. En palabras de "Paula", una diseñadora de software:

Estas empresas tienen otros estándares de trabajo. [...] Es un muy buen fogueo trabajar con marcas grandes, clientes grandes. Te das cuenta de que lo que se hace acá [en Costa Rica] no es de menor calidad que lo que se hace en cualquier lado (entrevista personal, 26 de marzo de 2015).

Desde este punto de vista, la experiencia de trabajo con multinacionales revela las calidades de Costa Rica como país productor de tecnología. 
En cambio, otros se muestran menos entusiastas. Según “Guillermo”, un desarrollador de software, "[Aprendí] que no quiero trabajar en compañías como esas, que no quisiera que en Costa Rica hubiera ese tipo de compañías" (entrevista personal, 23 de junio de 2015). La principal crítica formulada a las multinacionales se refiere a la poca oportunidad de contribuir al proceso creativo y estratégico de desarrollo tecnológico que se le otorga a los trabajadores en Costa Rica. Por esta razón, algunos actores caracterizan a las multinacionales de "maquilas" digitales o "productoras". La creación de proyectos locales (incluidas startups) es una forma de reivindicar las condiciones del país para participar en todas las fases de desarrollo de una tecnología.

En segundo lugar, existe una falta de articulación y de relaciones entre los actores y las lógicas institucionales que constituyen el campo. A esta misma conclusión han llegado diversas investigaciones (utilizando metodologías distintas); por ejemplo, un estudio desarrollado por colaboradores de distintas organizaciones concluyó en 2009 que "se requiere establecer una estrategia de cooperación entre el sector privado, el Estado y otros sectores de la sociedad para garantizar la sostenibilidad de las industrias TIC que sean relevantes para el desarrollo de Costa Rica" (Pinto et al., 2009: 56). Recientemente, al asumir que Silicon Valley resulta efectivamente el modelo a seguir en América Latina, Ciravegna (2012) afirmó:

Para desarrollar clusters de tecnología comunicación que sean altamente interconectados en red [...] los países latinoamericanos necesitan ayudar a sus compañias domésticas, inversionistas, universidades y centros de investigación a adquirir la capacidad de negociar con socios potenciales de la red, al interior y fuera del país (8).

Aunque en el discurso se considera vital la formación de conexiones estratégicas entre las lógicas que sustentan el campo, en la práctica estas lógicas están altamente desarticuladas.

En el marco de esas dos tensiones históricas -la diferencia de condiciones para empresas locales e internacionales y la falta de articulación entre actores-, resulta sorprendente la relativa carencia de política pública para el desarrollo de este sector en el país. La falta de articulación en el campo requiere de condiciones apropiadas para que cada uno de los actores implicados pueda identificar los beneficios (más que las limitaciones) de establecer nexos con otros participantes.

Esta visión es consistente con la propuesta de Ciravegna (2012) de pensar el campo como una red de actores interconectados, en la cual las responsabilidades están distribuidas más que concentradas en un nodo particular. Hasta la fecha, las condiciones para que esto se produzca han tendido a favorecer principalmente a grandes organizaciones multinacionales. Esta preferencia ha tenido diversas implicaciones. Destacan los aportes que realizan este tipo de organizaciones a la economía nacional 
(evidenciada por la creación de más de 50000 puestos de empleo en el sector de servicios en 2016) (Núñez Chacón, s. f.: párr. 18).

Como señala Ampuja (2016), la postura que ve a cualquier forma de participación estatal como "un compuesto de estructuras burocráticas que se interponen en el camino del espíritu emprendedor de la innovación" (32) ha ganado auge -Ampuja la denomina "fetichismo de la innovación"-. Por el contrario, se considera que las políticas públicas pueden alterar estructuralmente las condiciones para la formación de nexos entre actores y la consolidación de la red de producción de tecnología en el país (c.f. Mazzucato, 2013). Además, podrían facilitar la creación de mejores circunstancias para que proyectos e iniciativas locales de distintas escalas tengan acceso a opciones financieras apropiadas para el tipo de trabajo que realizan.

En la medida en que la lógica del emprendedurismo ha encontrado su momento en Costa Rica, diversos actores han apuntado a la posibilidad de transformarla en el eje vertebral de una agenda nacional de desarrollo. Al referirse a la variedad de iniciativas de emprendedurismo existentes en el país, el periódico La Nación celebraba en setiembre de 2015 la consolidación de oportunidades que "contribuyen a impulsar un elemento central de una estrategia exitosa de desarrollo en el mundo contemporáneo: la generación de valor agregado a partir de conocimientos propios que puedan patentarse y desarrollarse" (La Nación, 2015: párr. 4). A pesar de la juventud de estas iniciativas, el periódico concluía, "nos estamos acercando a la creación de un ecosistema más robusto de investigación, desarrollo, inversión y comercialización con base científica y tecnológica" (La Nación, 2015: párr. 7).

Sin embargo, el presente análisis evidencia que la producción de tecnología en Costa Rica no se ha pensado sistemáticamente como parte de un proyecto de sociedad. Al perseguir el sueño de querer transformar a Costa Rica en una "nación startup" (Amsel, 2015), la disposición actual del campo tiende a favorecer a ciertos actores más que a otros -como se discutió en párrafos anteriores-y a limitar el universo de posibilidades de desarrollo que podrían imaginarse.

En este sentido, más que iluminar un modelo o un conjunto de estrategias de desarrollo, el deseo de convertir a Costa Rica en un "Silicon Valley latinoamericano" podría estar contribuyendo a invisibilizar escenarios alternativos para pensar el presente y futuro del campo. Al tratar de reproducir en pequeña escala este ideal, la aspiración de ser una versión tropical de Silicon Valley quizás ha estado contribuyendo a desatender otras posibilidades más acordes a las dinámicas sustantivas sobre las que ha reposado el desarrollo histórico del campo. Como alternativa, se sugiere que un "modelo" propio para continuar configurando un sector productivo alrededor de tecnología de comunicación en Costa Rica yace en una mejor comprensión de dinámicas locales antes que en la imitación superficial de experiencias extranjeras. 


\section{ANEXO}

LISTA DE PERSONAS ENTREVISTADAS ${ }^{16}$

\begin{tabular}{|c|c|}
\hline Nombre & Organización \\
\hline Acuña, Alejandro & elastica \\
\hline Barrantes, Pablo & InterGraphicDesigns \\
\hline Bonilla, Juan José & Possible \\
\hline Calvo, Marco Antonio & Banco Central, IBM, MAI, United Fruit Co. \\
\hline Camacho, Kemly & Sulá Batsú \\
\hline Cambronero, Cristian & Big Web Noise \\
\hline Cayasso, José & Slidebean \\
\hline Corrales, Gilbert & Leaf \\
\hline Domb, Ana & Universidad Véritas \\
\hline Escudé, Laura & SweetRush \\
\hline Faba, Elena & Darwin \\
\hline Fervoy, Paul & MiWeb Digital Marketing \\
\hline Fuentes, Cristhian & Orson \\
\hline García, Adrián & Carao Ventures \\
\hline Gibson, Vanessa & CINDE \\
\hline Gutiérrez, José René & Manatí \\
\hline Herrera, Rafael & UCR-Escuela de Administración de Negocios \\
\hline López, Mariana & Consultora/UCR-Escuela de Ciencias de la Computación \\
\hline Mojarro, Irene & Procomer \\
\hline Monge, Ricardo & CAATEC/ITCR \\
\hline Peralta, Javier & Possible \\
\hline Pinto, Claudio & Exactus/Fair Play Labs \\
\hline Rivera, Otto & CAMTIC \\
\hline Urcuyo, Carolina & CINDE \\
\hline Villalobos, Néstor & Interaction \\
\hline Zuleta, René & Possible \\
\hline
\end{tabular}




\section{Notas}

1 Según Camacho (2010), “En América Central la exportación de productos de alta tecnología alcanza, sumando los cinco países, el 61\% del total de las exportaciones de la región" (2). Sin embargo, esta cifra está distribuida de manera desigual en la región. Costa Rica representa casi el 74\% de ese monto. Panamá es el otro país de la región que ha recibido atención como potencial centro de desarrollo tecnológico. Al igual que Costa Rica, aunque de manera más reciente, Panamá se ha enfocado en iniciativas de atracción de inversión extranjera directa (Padilla y Martínez, 2007). Otros factores que se destacan son la relativa inversión en educación y la existencia de fondos públicos para investigación (Casalet y Buenrostro, 2014). La revista The Economist reflexionaba en 2011 sobre las posibilidades de Panamá de convertirse en el "Singapur centroamericano". En un artículo derivado de esta publicación, investigadores concluyeron que "los avances logrados [por Panamá] son encomiable[s], sin embargo, se consideran insostenibles en ausencia de inversión [en] una industria TIC de producción local enfocada a la exportación" (Murillo, Zuñiga y Chen, 2013). Dada las pocas publicaciones existentes, se considera que la investigación comparativa sobre este tema en la región constituye una importante avenida futura de investigación.

2 Sharma (2015) realiza un ejercicio similar en el caso de India.

Las personas entrevistadas se seleccionaron luego de combinar dos formas de muestreo. Inicialmente, con el propósito de tener variedad en la muestra, se contactaron a personas de diferentes tipos de organizaciones (multinacionales, empresas locales, freelance...) que realizaran distintos tipos de actividades (programación, diseño, administración de proyectos, gerencia, inversión, emprendimiento, intermediación...) y tuvieran varias trayectorias en el campo laboral (algunos de los primeros programadores del país, fundadores de primeras empresas de producción de tecnología, personas que ingresaron al campo más recientemente, estudiantes...). En segundo lugar, se procedió a implementar el muestreo de "bola de nieve" para identificar a otros profesionales que cumplieran con estos criterios y fueran recomendados por otros entrevistados.

Ciravegna (2012) define un cluster como "aglomeraciones de compañías y organizaciones involucradas en la producción de bienes y servicios relacionados" (5).

Para Rodríguez Clare (2002), la importancia de iniciativas de educación en la formación del campo también puede ilustrarse por la apertura de laboratorios de cómputo en escuelas del país, la creación de universidades privadas y el inicio de colegios técnicos.

Para una discusión más extensa sobre las iniciativas gubernamentales desarrolladas en la década de los ochenta y principios de los noventa con el propósito de estimular el uso de tecnología de comunicación en el país, véase Fonseca (1991), Monge (2002), Monge et al. (2015) y Siles (2008).

Como se detalla en la conclusión del artículo, el objetivo de obtener IED no ha estado desprovisto de controversia. Para algunos, este proyecto ha significado de manera paralela una supresión de la industria local (Monge-González et al., 2015; Nicholson y Sahay, 2009b; Pinto et al., 2009).

A pesar de su importancia (material y simbólica) para el desarrollo del campo, la versión local de la "burbuja del .com" ha sido poco explorada por la investigación académica. 
9 El giro hacia una política de inclusión de otro tipo de organizaciones, además de la producción de software, y hacia un desarrollo orientado más a la exportación que a la producción local, involucró la salida de algunos de los miembros originales de la Cámara (Nicholson y Sahay, 2009b).

Esta es, probablemente, la cita más recurrente en la literatura sobre la producción de tecnología en Costa Rica. Fue identificada durante esta investigación en una variedad de informes y trabajos sobre el tema de distintas décadas (Brenes y Govaere, 2008; MICIT, 1990; Monge, 2002).

11 Con el inicio de la nueva década, CINDE reenfocó sus esfuerzos en la atracción de inversión extranjera en sectores más especializados de trabajo (tales como investigación y desarrollo, análisis de datos y computación en la nube, entre otros).

Este giro ha caracterizado a una variedad de países y regiones en el mundo (Takhteyev, 2012; Zhou, 2008).

Boltanski y Chiapello (1999) analizan con más profundidad el rol que ha jugado la noción de emprendedurismo en la reconfiguración del capitalismo desde finales del siglo XIX.

14 Del mismo modo, las virtudes de formar parte de cámaras empresariales o de contar con un portavoz de los intereses del campo están menos claras para algunos creadores de startups en el país. En conjunto, estas relaciones entre startups y otras empresas en el sector sugieren que existen tensiones entre lógicas institucionales distintas al interior del campo.

En su estudio del aporte de multinacionales al campo de producción de tecnología en el país, Monge, Hewitt y Torres (2015) concluyen que pueden encontrarse "impactos positivos de la presencia de [multinacionales] en la supervivencia y el crecimiento de empresas domésticas de TIC mediante cadenas de suministro", pero que al mismo tiempo "hay pocos vínculos productivos entre multinacionales y empresas locales [...] y sólo algunos beneficios no-económicos (externalidades) derivadas de esta relación" (57).

Solo se menciona a las personas que aceptaron ser identificadas por su nombre real en cualquier producto derivado de la investigación.

\section{Bibliografía}

Alonso, Eduardo. “Tendencias de la inversión extranjera en Costa Rica: Efectos de la reforma de la ley de zonas francas". Estado de la nación en desarrollo humano sostenible: Decimoctavo informe. San José (Costa Rica): Estado de la Nación, 2012.

Ampuja, Marko. "The new spirit of capitalism, innovation fetishism and new information and communication technologies". Javnost: The Public 23, 1 (2016): 19-36.

Amsel, Jaime.¿Qué hace a Israel una nación start-up y qué puede hacer Costa Rica al respecto? Conferencia presentada en la Universidad Nacional, Heredia, Costa Rica, 17 ago. 2015.

Arora, Ashish, y Gambardella, Alfonso. From underdogs to tigers: The rise and growth of the software industry in some emerging economies. Oxford: Oxford University Press, 2005.

Baraya, Aristides R.; Brenes, Lizette y Budden, Michael Craig. "Strategically strengthening the software export sector: A benchmarking comparison of national experience". International Business \& Economics Research Journal 7, 10 (2008): 1-6.

BBC. “¿Cuál es el Silicon Valley latinoamericano”. BBC.com, 15 oct. 2012. <http://www.bbc. com/mundo/noticias/2012/10/121015_tecnologia_silicon_valley_america_latina_dp>. 
Boczkowski, Pablo J. y Siles, Ignacio. "Steps toward cosmopolitanism in the study of media technologies: Integrating scholarship on production, consumption, materiality, and content". En Tarleton Gillespie, Pablo J. Boczkowski y Kirsten Foot (Eds.), Media technologies: Essays on communication, materiality and society. Cambridge, MA: MIT Press, 2014. 53-75.

Boltanski, Luc y Chiapello, Eve. Le nouvel esprit du capitalisme. París: Gallimard, 1999.

Brenes, Lizette y Govaere, Velia. "La industria del software en Costa Rica". Comercio Exterior 58, 5 (2008): 303-311.

Calderón, Marta Eunice. Fundación, retos y primeros logros de la Escuela de Ciencias de la Computación e Informática. Ponencia presenteda en la XXXVIII Conferencia Latinoamericana en Informática, Medellín, Colombia, 1-5 oct. 2012a.

Calderón, Marta Eunice. Jorge González Martén, pionero costarricense de la computación. Ponencia presentada en la XXXVIII Conferencia Latinoamericana en Informática, Medellín, Colombia, $1-5$ oct. $2012 b$.

Callon, Michel. "Some elements of a sociology of translation: Domestication of the scallops and the fishermen of Saint Brieuc Bay". En John Law (Ed.), Power, action and belief: A new sociology of knowledge? London: Routledge and Kegan Paul, 1986. 196-233.

Camacho, Kemly. "Emprendimientos de mujeres basados en TIC: Una definición”. Documento inédito, Sulabatsu.com, 2010. <http://sulabatsu.com/wp-content/uploads/2010emprendimientos_mujeres_basados_tic_definicion.pdf $>$.

CAMTIC. Costa Rica: Verde e Inteligente. Estrategia nacional de tecnologías de información y comunicación (Resumen ejecutivo). San José: CAMTIC, 2004.

CAMTIC. Estado nacional de software 2005: Estadísticas sectoriales de Costa Rica. San José: CAMTIC, 2005.

CAMTIC. Costa Rica: Verde e Inteligente 2.0 (Resumen ejecutivo). San José: CAMTIC, 2009.

CAPROSOFT. "Nuestra misión”. Caprosoft.org, 2014. <https://web.archive.org/ web/20040730010816/http://www.caprosoft.org/sobre1.htm>.

Casalet, Mónica y Buenrostro, Edgar. “La integración regional centroamericana en ciencia, tecnología en innovación: un nuevo desafío". Economía: Teoría y Práctica 40, (enerojunio 2014): 165-193.

Cayasso, Jose. "Startups vs PYMES". Medium.com, 2015. <https://medium.com/@cayajose/ startups-vs-pymes-c113a4d3b1c3>.

Ceruzzi, Paul E. A history of modern computing. Cambridge, MA: MIT Press, 1998.

Chacón Jiménez, Krisia. “Podrá Costa Rica convertirse en un Silicon Valley?”. El Financiero. 18 ago. 2015. <http://www.elfinancierocr.com/tecnologia/Podra-Costa-Rica-SiliconValley_0_794920505.html>.

Chaves, Luis. Propuesta de una politica nacional en Informática para Costa Rica (Tesis sometida a la consideración de la Comisión del Programa de Estudios de Posgrado en Administración Pública para optar por el grado de Magister Scientiae). San José: Universidad de Costa Rica, 1990.

Ciravegna, Luciano. Promoting Silicon Valleys in Latin America: Lessons from Costa Rica. London: Routledge, 2012.

Condo, Arturo; Sanz, Luis J. y Williams, Thomas. “Mora and Beck: Lessons from investors in Costa Rica's knwoledge economy". En Elizabeth F. O'Halloran, Peter L. Rodriguez y Felipe Vergara (Eds.), An executive briefing on angel investing in Latin America. Charlottesville, VA: Darden Business, 2005. 171-178. 
Conway, Moody's Analytics, Tractus, Oxford Economics. The world's most competitive cities. Peachtree Corners, GA: Conway, 2015.

Cordero, José y Paus, Eva. “Foreign investment and economic development in Costa Rica: The unrealized potential”. En Kevin P. Gallagher y Daniel Chudnovsky (Eds.), Rethinking foreign investment for sustainable development: Lessons from the Americas. London: Anthem, 2009: 97-124.

DiMaggio, Paul J. y Powell, Woody W. “The iron cage revisited: Institutional isomorphism and collective rationality in organizational fields". American Sociological Review 48(2), 1983: 147-160.

Fonseca, Clotilde. Computadoras en la escuela pública costarricense: La puesta en marcha de una decisión. San José: Fundación Omar Dengo, 1991.

González Sandoval, Gilda. "Costa Rica destaca como primer exportador de alta tecnología en Latinoamérica y el cuarto en el mundo". El Financiero, 26 ene. 2014. <http://www. elfinancierocr.com/economia-y-politica/Alta_tecnologia-ciencias_de_la_vida-Cindeexportaciones_0_452354794.html>.

Hanson, Gordon. H. Should countries promote foreign direct investment?, G-24 Discussion paper series No. 9, 2001. <http://213.154.74.164/invenio/record/17103/files/gordon.pdf>.

Heeks, Richard y Nicholson, Brian. Software export success factors and strategies in 'follower' nations. Competition $\mathcal{E}$ Change 8, 3 (2004): 267-303.

Jara, Elena y Alvarez, Vivianne. Desarrollo de las TIC en Costa Rica y su tratamiento en el CAFTA. Working paper 98. Buenos Aires: Latin American Trade Network (LATN), 2008.

La Nación. "Investigar, crear, emprender". La Nación, 11 set. 2015. <http://www.nacion.com/m/ opinion/editorial/Investigar-crear-emprender_0_1511448846.html>.

Larraín, Felipe; López-Calva, Luis F. y Rodríguez-Clare, Andrés. “Intel: A case study of foreign direct investment in Central America". En F. Larraín (Ed.), Economic development in Central America, Vol. 1: Growth and internationalization. Cambridge, MA: Harvard University Press, 2001. 165-196.

Lebendiker Fainstein, Marcelo; Herrera González, Rafael y Velásquez López, Guillermo. Reporte nacional 2014: La situación del emprendimiento en Costa Rica. San José: Asociación Incubadora Parque Tec, 2015.

Lebendiker, Marcelo. "Parque Tec: A disciplined business incubator in Costa Rica". En Elizabeth. F. O'Halloran, Peter L. Rodríguez y Felipe Vergara (Eds.), An executive briefing on angel investing in Latin America. Charlottesville, VA: Darden Business, 2005. 179-182.

Lécuyer, Christophe. Making Silicon Valley: Innovation and the growth of high tech, 1930-1970. Cambridge, MA: MIT Press, 2006.

Mata, Francisco J.; Matarrita, Rosaura y Pinto, Claudio. "Assessing computer education in Costa Rica: Results of a supply and demand study of ICT human resources". CLEI Electronic Journal 5, 1 (2012): 1-18.

Mazzucato, Mariana. The entrepreneurial state: Debunking public vs. private sector myths. London: Anthem Press, 2013.

Medina, Eden. Big Blue in the bottomless pit: The early years of IBM Chile. IEEE Annals of the History of Computing 30 (2008): 26-41.

MICIT. Dimensión científica y tecnológica del desarrollo: Memoria 1986-1990. San José: MICIT, 1990. 
MIDEPLAN. Costa Rica: Contribución de las zonas francas en las áreas de menor desarrollo. San José: Ministerio de Planificación Nacional y Política Económica, 2008.

Monge, Jorge. "Industrial upgrading en el sector software en Costa Rica". En Juan Pablo Pérez Sáinz (Ed.), Encadenamientos globales y pequeña empresa en Centroamérica. San José: Facultad Latinoamericana de Ciencias Sociales, 2002. 19-106).

Monge-González, Ricardo y Hewitt, John. Innovación, competitividad y crecimiento: Desempeño de Costa Rica y de su sector de las TICs, Vol. 5. Costa Rica digital. San José: CAATEC, 2008.

Monge-González, Ricardo; Hewitt, John y Torres-Carballo, Federico. Do multinationals help or hinder local firms? Evidence from the Costa Rican ICT sector. Working paper. San José: CAATEC, 2015.

Murillo, Rodrigo; Zúñiga, Roy y Chen, Min. “¿Existe realmente un potencial Singapur centroamericano?". Strategy News, 2013. <http://www.strategybg.com/existe-realmente-unpotencial-singapur-centroamericano/>.

Nelson, Roy C. Harnessing globalization: The promotion of nontraditional foreign direct investment in Latin America. University Park, PA: Pennsylvania State University Press, 2009.

Nicholson, Brian y Sahay, Sundeep. "Human resource development policy in the context of software exports: Case evidence from Costa Rica". Progress in Development Studies 8, 2 (2008): 163-176.

Nicholson, Brian y Sahay, Sundeep. "Deinstitutionalization in the context of software exports policymaking in Costa Rica". Journal of Information Technology 24 (2009a): 332-342.

Nicholson, Brian y Sahay, Sundeep. "Software exports development in Costa Rica: Potential for policy reforms". Information Technology for Development 15(1), 2009b: 4-16.

Nixon, Patrick. "Camtic esboza beneficios del Cafta para la industria de TI". BNAmericas. com, 17 oct. 2007. <http://www.bnamericas.com/es/noticias/tecnologia/Camtic_esboza_beneficios_del_Cafta_para_la_industria_de_TI?idioma=es $>$.

Núñez Chacón, María. Exportaciones de Costa Rica se mantienen en alza. Semanario Universidad, 10 may. 2016. <http://semanariouniversidad.ucr.cr/pais/exportacionescosta-rica-se-mantienen-alza/>.

Padilla, Ramón y Martínez, Jorge Mario. Apertura comercial y cambio tecnológico en el istmo centroamericano. México, D.F.: Naciones Unidas, 2007.

Paus, Eva. Foreign investment, development, and globalization: Can Costa Rica become Ireland? New York: Palgrave Macmillan, 2005.

Paus, Eva y Gallagher, Kevin P. "Missing links: Foreign investment and industrial development in Costa Rica and Mexico". Studies in Comparative International Development 43, 1 (2008): 53-80.

Pérez Damasco, Diego. "Costa Rica busca convertirse en "Silicon Valley" latinoamericano". La Prensa Libre, 13 jul. 2015. <http://www.prensalibre.cr/Noticias/detalle/32712/323/ costa-rica-busca-convertirse-en-silicon-valley-latinoamericano>.

Petry, Petra y Lebendiker, Marcelo. El emprendedurismo en Costa Rica. Estado de la nación en desarrollo humano sostenible: Decimoséptimo informe. San José: Estado de la Nación, 2011.

Pinto, Claudio; Herrera, Rafael; Mata, Francisco J.; Matarrita, Rosaura; Salas, Iván y Jara, Elena. Formación de capital humano en el sector de TIC en Costa Rica. México, DF: Facultad Latinoamericana de Ciencias Sociales, 2009.

Porter, Michael E. y Ketelhohn, Niels W. “Building a cluster: Electronics and information technology in Costa Rica". Harvard Business School Case Studies (2002): 703-422. 
PROSIC. Hacia la sociedad de la información y el conocimiento en Costa Rica. Informe 2006. San José: PROSIC, 2006.

PROSIC. Hacia la sociedad de la información y el conocimiento en Costa Rica. Informe 2007. San José: PROSIC, 2007.

PROSIC. Hacia la sociedad de la información y el conocimiento en Costa Rica. Informe 2011. San José: PROSIC, 2011.

Rodríguez Clare, Andrés. "La estrategia tecnológica de Costa Rica: Raíces y resultados". Cooperación Sur 1 (2002): 94-107.

Rodríguez-Clare, Andrés. Innovation and technology adoption in Central America. Working paper 525. Washington, DC: Inter-American Development Bank, 2005.

Saliba, Frédéric. "Le Costa Rica se rêve en Silicon Valley d'Amérique latine". Le Monde, 5 mayo 2014. <http://www.lemonde.fr/economie/article/2014/04/05/le-costa-rica-se-reve-ensilicon-valley-d-amerique-latine_4396329_3234.html>.

Sanz, Luis J. y Lessiza, Mateo. Lidersoft. Journal of Business Research 66, 3 (2013): 456-462.

Sanz, Luis J. y Porras, Román E. "Costa Rica: IT entrepreneurs leapfrogging for innovations". En Esteban R. Brenes y Jerry Haar (Eds.), The future of entrepreneurship in Latin America. New York: Palgrave Macmillan, 2012: 166-189.

Saxenian, AnnaLee. Regional advantage: Culture and competition in Silicon Valley and Route 128. Cambridge, MA: Harvard University Press, 1994.

Saxenian, AnnaLee. The new argonauts: Regional advantage in a global economy. Cambridge, MA: Harvard University Press, 2006.

Scott, W. Richard. Institutions and organizations. Thousand Oaks, CA: Sage, 2014.

Sharma, Dinesh. C. The outsourcer. Cambridge, MA: MIT Press, 2015.

Siles, Ignacio. Por un sueño en.red.ado. Una historia de Internet en Costa Rica (1990-2005). San José: Editorial de la Universidad de Costa Rica, 2008.

Siles, Ignacio. "Establishing the Internet in Costa Rica: Co-optation and the closure of technological controversies". The Information Society 28, 1 (2012): 13-23.

Silva, Leiser y Figueroa, Eugenio B. "Institutional intervention and the expansion of ICTs in Latin America: The case of Chile". IT \& People 15, 1 (2002): 8-25.

Spar, Debora. Attracting high technology investment: Intel's Costa Rican plant. FIAS Occasional Paper 11. Washington, DC: World Bank, 1998.

Takhteyev, Yuri. Coding places: Software practice in a South American city. Cambridge, MA: MIT Press, 2012.

The Economist. A Singapore for Central America?, 14 jul. 2014, 44.

van der Laan, Elise y Kuipers, Giselinde. "How aesthetic logics shape a cultural field: Differentiation and consolidation in the transnational field of fashion images, 19822011". Poetics 56 (2016): 64-84.

Vargas, Monserrath. "Programa de Silicon Valley planea abrir en Costa Rica". La Nación, 13 ago. 2014. <http://www.nacion.com/vivir/ciencia/Programa-Silicon-Valley-CostaRica_0_1432656730.html>.

Vogel Jr., Thomas. "Costa Rica succeeds in attracting investment from high-tech firms". The Wall Street Journal, 2 abr. 1998. <http://www.wsj.com/articles/SB8914694306530500>.

Williamson, John. "What Washington means by policy reform". En John Williamson (Ed.), Latin American adjustment: How much has happened? Washington, DC: Institute for International Economics, 1990. 7-33. 
Zhou, Yu. The inside story of China's high-tech industry: Making Silicon Valley in Beijing. Lanham: Rowman \& Littlefield Pub, 2008.

Ignacio Siles González. Costarricense. Doctor en Medios, Tecnología y Sociedad (Northwestern University, EE. UU.). Es profesor catedrático de la Escuela de Ciencias de la Comunicación Colectiva e investigador del Centro de Investigación en Comunicación (CICOM), ambos de la Universidad de Costa Rica. Autor del libro Por un sueño en.red.ado: Una historia de Internet en Costa Rica (EUCR, 2008) y de varios ensayos sobre la relación entre tecnología, comunicación y sociedad.

Contacto: ignacio.siles@ucr.ac.cr

Johan Espinoza Rojas. Costarricense. Bachiller en Ciencias de la Comunicación Colectiva de la Universidad de Costa Rica y de Sociología en la Universidad Nacional. Investigador del Hormiguero de Investigación del Centro de Investigación en Comunicación (CICOM). Posee varias publicaciones que refieren a la epistemología y la metodología de la comunicación.

Contacto: johanespinozarojas@gmail.com

Andrés Méndez Marenco. Costarricense. Estudiante de Ciencias de la Comunicación Colectiva de la Universidad de Costa Rica. Investigador del Beta Lab: Laboratorio de Interactividad para la Comunicación. Ha trabajado como asistente de investigación para el Programa Sociedad de la Información y el Conocimiento (PROSIC) y Centro de Investigación en Comunicación (CICOM).

Contacto: jose.mendezmarenco@ucr.ac.cr 
